\title{
Determinants of Core Competencies of School Leaders Managing Philippine Schools Overseas: A Guide to Stakeholders and School Owners
}

\author{
Gerardo P. Macasa Jr. ${ }^{1, *}$, Imee C. Acosta ${ }^{1,2}$, Eduardo P. Malagapo ${ }^{1,3}$ \\ ${ }^{1}$ Graduate School, Philippine Christian University, Philippines \\ ${ }^{2}$ Fashion \& Graphic Design, Virginia Commonwealth University-Qatar, Qatar \\ ${ }^{3}$ Administration, Al Andalus International School, Kingdom of Saudi Arabia
}

Copyright $\mathrm{C} 2019$ by authors, all rights reserved. Authors agree that this article remains permanently open access under the terms of the Creative Commons Attribution License 4.0 International License

\begin{abstract}
School leaders play a significant role in managing and leading the school, not only to excel in its entire academic program but equally important is its growth and sustainability. This research is intended to provide a source of realistic and useful ideas to owners and stakeholders about the importance of determining core competencies of school leaders to meet the qualifying standards in appointing or employing school officials in order to help and guide them in choosing the right and competent members of school leaders that suit well in managing Philippine Schools Overseas. The study is quantitative descriptive using survey design and the result of the study uncovered the essential core competencies of school top executives, namely: leading people and business coalition as core qualifications; and conciseness and composure as emulating attributes that determined the necessary core competencies for school managers. Successful school leaders that possess all the relevant core competencies identified in this study are able to drive transformation and school improvement. They effectively influence a variety of school outcomes, and this entails cultivating leadership in others so they can assume their parts in realizing the school vision and help organizations to articulate strategy and link behaviors to PSO's vision and mission.
\end{abstract}

Keywords School Leadership Qualifications, Emulating Attributes, Core Competencies, Philippine Schools Overseas

\section{Introduction}

The Commission on Filipinos Overseas (CFO) estimated that approximately 10.2 million Filipinos worked or resided abroad in 217 different countries. This is about eleven percent $(11 \%)$ of the total Philippine population, which was estimated by the Philippine Statistics Authority to be 92.34 million in 2010 [1]. With a constantly growing population of Filipinos working abroad, Philippine School Overseas (PSOs) were established to address the educational needs of Filipino overseas' children. The PSOs are private educational institutions that are fully or partially-owned and/ or managed by Filipinos. These schools, which follow the prescribed Philippine curriculum, are required to secure permits to operate and be recognized both by the Philippine Department of Education and its counterpart institution in the host countries. Dependents of overseas Filipinos, who studied in PSOs can easily reintegrate into the Philippine educational system upon their return to the home country. As of 2015, there are forty (40) PSOs in ten (10) countries - Bahrain, China, East Timor, Greece, Kuwait, Libya, Oman, Qatar, Kingdom of Saudi Arabia, and United Arab Emirates. Of these schools, thirty-five (35) have Certificates of Recognition or Government Permits issued by the Philippine Department of Education (DepEd) and six (6) have provisional permits [2]. Currently, there are an estimated 32,000 students enrolled in PSOs at various levels, from pre-elementary, elementary, and high school [3]. What is critical among PSOs is the composition of the members of the school leadership that manage and govern the school. Every school should be manned by qualified and competent school leaders, such as the School Principals, Vice-Principals, and Department/ Unit Heads/ Coordinators as they play a vital role in developing policies and procedures that will be used as guiding principle to make sure that the school is well led and properly managed. Mehri and Ramezan's [4] study corroborated that the quality of school leadership is one of the basic factors that significantly influence the school's capacity to attain its vision, mission, goals, and objectives. Although, several studies have been conducted already to investigate the 
determinants of leadership core competencies, but the applicability of such research in managing Philippine Schools Overseas still remains underexplored. Hence, this paper aims to answer the question, "what are the determinants of core competencies of school leaders in managing PSOs?" It also intends to provide the source of realistic and useful ideas to stakeholders regarding the criteria, ability, skills, and educational qualifications of school leaders as a requisite to help and guide the owners in choosing the rightful and competent members of school leadership that befit well in managing Philippine established schools overseas. It is hoped that the findings of this study would serve as an elemental source to raise awareness of school hiring officials about the importance of determining core competencies of school leaders to meet the qualifying standards in appointing or employing school officials as an assurance of competence, quality, and leadership skills or ability.

\section{Theoretical Framework}

The theoretical insights of this research were partly derived from leadership theories that are relevant to the main problem of the study. The Trait Theory of Leadership $[5,6]$; the Functional Leadership Theory $[7,8]$; and the Leadership Skills Theory [9] were used to support this study.

Trait theory of leadership is seen as inherent that is based on the premise that leaders are born, not made [10]. Proponents of this theory, Stodghill's [5] and McCall's [6], believed that a person's ability to lead is something that people are born with and not something that could be developed. It specifies the personality traits that distinguish leaders from non-leaders making them successful leaders with the assumption that those in leadership position would display more of those traits than those in the subordinate positions. As such, leaders tend to show higher traits in terms of self-confidence, assertiveness, decisiveness, trustworthiness, creativity, task competence, etc. $[10,11$, 12]. These personality traits were categorized by Allport [13] into three distinct categories, namely: (1) cardinal traits that shape the leader's actions; (2) central traits are common in most people; and (3) secondary traits that are used by leaders in certain situations [14]. To utilize this theory in educational setting, this served as the basis for the factors that determine the emulating attributes of leaders so as to determine the attributes that are valued in them, such as, credibility, conviction, clarity, confidence, composure, connection, charisma, and conciseness.

The functional leadership theory McGrath [8] served as the anchorage to identify the core qualifications of a leader, such as leading change, leading people, results driven, business acumen, and business coalition. In this theory, it focuses on what the leader has to do to ensure that all requirements of the group are met so that goals can be achieved [12]. It further suggests that the leadership role is to do, or get done, whatever is not being adequately handled for group needs [8]. In this theory, the leader is seen as completer, the best that a leader can do is to observe which functions are not being performed by a segment of the group and enable this part to accomplish them [15]. As formulated by McGrath, the functional approach is generic it could apply to anybody leading a team, the purpose of this leadership approach is to identify the critical functions that need to be fulfilled if a work group in an organization is to perform effectively [7]. The functional style assumes that leadership is defined by the behavior of the leader and its corresponding effect on the group [15]. It focuses on the area that a leader must address to be effective. If a leader manages, by whatever means, to ensure that all functions critical to both task accomplishment and group maintenance are adequately taken care of, then the leader has done his or her job well [7]. Thus, functional leadership is something that any leader provides to a group to meet certain needs.

The leadership skills theory implies that learned skills, a developed style, environmental influences, acquired knowledge and experiences are the real keys to leadership performance $[17,18,19]$. These skills and abilities are learned and can be developed; thus, many people have leadership potential if they can achieve the required skills and abilities through developmental stages, observation, and practice; and then, they can become more effective leaders [20]. This is particularly important for leadership educators whose very work involves developing those skills and abilities in others [14]. Leadership skills theory further suggest that one's career experiences, and environments influence a leader's development of skills and competencies [21]. Accordingly, Mumford, Zaccaro, Harding, et. al. [9] identified seven leadership skills: problem-solving skills, social judgment skills, knowledge, general cognitive skills, crystallized cognitive skills, motivation, and personality. The concepts presented in skills theory are important to understand the approaches of skills-based to leadership. In this study, this theory was used to identify the factors of the core competencies of a leader that comprised the skills, although the listing is somewhat expanded, as to team leadership, collaboration and influence, strategic orientation, customer impact, people \& organization development, results orientation, change leadership, commercial orientation, and market knowledge.

\section{Literature Review}

\subsection{Core Qualification}

Core qualification refers to the special qualities and characteristics that are required from a leader to bring organizational success [22]. Leading change, leading 
people, results driven, business acumen, and business coalition are the core qualifications considered in this study. Change leadership is the capacity to lead people in complex social systems, such as teams, businesses, and organizations, on developmental journeys from where they are now towards better and exciting futures [23]. The change leader should inspire others into new ways of thinking and doing business, because no business or any other institution survive over the long term if it will not reinvent, innovate, seek new opportunities and improve its business operation to keep pace with the current economic demand and trend [24]. A school leader, should also learn how to build a team that will adequately provide support and help manage the academic institution [25, 26]. The core qualification of being results driven involves the ability to meet organizational goals and customer expectations [27]. A member of the governing board should have the capacity to make decisions that produce high-quality results by applying technical knowledge, analyzing problems, and calculating risks [28]. Essentially, a leader should consider himself or herself and others as accountable for measurable high-quality, timely, and cost-effective results. Business acumen is one of the key competencies that every leader in every organization needs to possess. It is the innate ability, knowledge and understanding of financial, accounting, marketing, and operational functions of the organization; and the ability to make accurate, just business choices, decisions and judgment [29]. In addition to soft skills, business acumen has also been identified as crucial to being well- rounded in the school industry where school leaders are required to possess the ability to explain how their business entity goes to market, understand business operations, apply financial data, use business terminology to gain credibility, recognize business priorities, create a value proposition, determine the competitors, and advance the learning and performance business agenda [30]. The higher up a leader goes in any organization; the more relational skills and business connections are needed. With this, a leader is able to establish connection cultures that contribute positively to the organization's performance because leadership has everything to do with how you relate to others and the powerful connections of those relationships [31].

\subsection{Emulating Attributes}

A leader's emulating attributes play a very important role in enhancing employee job satisfaction, work motivation and work performance. Leaders with emulating attributes accelerate the development of most organizations [32]. The emulating attributes considered in this study are composure, connection, charisma, confidence, credibility, clarity, conviction, and conciseness. Leaders need to show more composure than ever before in the workplace [33]. Composure is appropriately defined as a mean evenness of mind under stress. It is a habit of mind that is only rarely disturbed under great strain [34]. How leaders respond to any economic turmoil and other growing business pressures reflects the leader's readiness, good business wisdom and understanding. Darrat et. al., [35] perceived that personal interactions are often charged with emotions and laden with conflicts. Hence, the leaders' ability to maintain composure and resolve difference under pressure is valuable to maintaining good relationship. Leadership is a relationship between those who aspire to lead and those who choose to follow. Strategies, tactics, skills, and practices are hollow and fruitless unless the fundamental human aspirations that connect leaders and their constituents are understood and appreciated [36]. A leader should be able to assess whether they have the ability to make connections beyond just their level of competence [37]. These connections according to Brookhart [38] are very powerful since they go beyond just the manager and the employee relationship because in today's environment, effective leaders must ensure that their organizations have a close bond with the community they serve. Mortensen [39] defines charisma as the ability to easily build rapport, effectively influence others, inspire them to achieve more, and in the process make allies for life. Charisma can be a huge asset in improving manager-subordinate relationships, or leading other people since charisma makes a leader become more influential, more persuasive, and more inspiring. Therefore, charisma is not a gift. It is a leadership tool [40]. When a leader exhibits confidence, trust is easier gained. Having a trusted and confident leader is critical to the success of any organization [41]. Confidence, on one hand, is the cornerstone of leadership. Being confident teaches a leader to be an effective problem solver, more decisive, a better communicator, an excellent coach and mentor, and holds the team members accountable [42]. On the other hand, credibility is the foundation of leadership. Credible manager allows the subordinates to look at the leader as a reliable resource for information and decision making. Developing a reputation for giving honest and truthful information that can be verified if necessary, goes a long way towards gaining employee respect and establishing credibility [43]. Clarity implies emphasizing on a specific message or goal at a time, rather than trying to achieve a lot at once. Clarity in communication makes understanding easier. It has a complete clearness of thoughts and ideas that enhance the meaning of the message $[36,44]$. A clear message makes use of exact, appropriate and concrete words. In business communication, there is only one chance to make one's point. A business communication possesses clarity when it is expressed in a language and transmitted in a way that will be comprehended by the receiver. Leaders must take time to review their communications strategy and so that ideas are properly communicated $[45,46,47]$. Conviction is a threshold level wherein one feels a high degree of 
confidence about what one actually believes should be done. A leader who can demonstrate conviction will be more successful, and so will everyone working with him $[48,49]$. In business, it pays to get to the point quickly hence, school leaders should be concise in communicating what he wants to convey in the least possible words because conciseness is a necessity for effective communication Effective business communication uses concise and straightforward language that gets the point across completely and in a manner that encourages efficient action. Concise communication is both time-saving and cost-saving [50,51].

\subsection{Core Competencies}

Literature suggests that leaders have significant influence on subordinates. The significance of leadership core competencies in the education sector has a direct impact on organizational development [52]. Strategic orientation, customer impact, market knowledge, commercial orientation, results orientation, change leadership, collaboration and influence, people and organizational development, and team development are the core competencies ruminated in this study. Strategic Orientation is the leader's ability to link long-range visions and concepts to daily work [53]. It implies the ability to think conceptually and to "see the big picture". It involves taking calculated risks based on an awareness of societal, economic and political issues as they impact the strategic direction of the department and the organization [53]. A school leader has to recognize and value the impact and importance of customers to every business activity - may it be a profit or non-profit oriented business activities. Excellent customer service is the lifeblood of any business [54]. The essence of good customer service is forming a relationship with customers - a relationship that the individual customer feels that he would like to pursue [55]. School leaders who excel at understanding their company's market can make strategic decisions about latest development in education and business trends. Market knowledge is about understanding the market context in which a business operates. Competence in market knowledge is usually a requirement of the leadership competencies of strategic orientation [56]. Leaders with substantial market knowledge leads the organization to better positioning on the market in the sense that it tends to maximize the approach on how to produce an offer that is designed based on the preferences of the target market [57]. Commercial orientation, also known as commercial awareness is the knowledge of how businesses make money, what customers want, and what problems there are in a particular area of business. In other words, commercial orientation is an understanding of what the organization needs to do to be profitable, to be successful, and to serve its customers well. With it, a leader should know the organization's core values, biggest competitors, key stakeholders, and current business challenges, including the organization's strengths and weaknesses, and be able to use that information to make sensible decisions [58]. Creating a result-oriented culture of an institution doesn't start by finding the most talented and work-experienced people. According to Huber [59] it begins by defining the results you want to achieve and then finding people who are capable and motivated of reaching them. To successfully achieve the desired outcome, Abbas and Riaz [60] suggested that it would be better to explain the results required first and then find people who will excel at achieving them. Change leadership and leadership development are critically important to the continuing success of an educational institution everywhere. Transactional and transformational leadership, the more traditional models, are no longer adequate to meet the pressing financial and operational challenges. Current and aspiring leaders must understand the culture of change that permeates school organizations and embrace the opportunities inherent in that culture (Cloud, 2010) [61]. School leaders should always share the change leadership tools, strategies and innovative practices that the staff can quickly adopt to lead change and innovation successfully and to keep abreast with today's fast-paced business environment $[62,63]$. Collaboration and influence involve working indirectly, through persuasion and trust, rather than by formal authority. The leadership competency of collaboration and influence refers to the school leader's ability to work with peers, partners and others who are not in their line of command and to positively impact business performance. Organizations live or die on relationships [64]. The ability of school managers to create successful collaborative relationships can sometimes make or break the existence and success of the school [47]. Crucial to the success of the school is for the school managers to be competent and possess the skills to define and support in developing and further enhance the talent and expertise of their staff [65]. This practice according to Bassi \& McMurrer [66] involves providing current training and advanced professional opportunities to their workers. School leaders should enlighten and clarify existing policies and procedures by offering support and guidance on a range of staffs' health and well-being initiatives. People capability enhancement induces better knowledge, skill and aptitude and it develop better business opportunities during global change [67]. This highlights the importance of a school leaders' possessing the relevant competencies, values, and personalities in dealing with team leadership. Leading a team is critical in any activities or endeavor [68]. Lastly, teamwork is also considered as vital in every group or business activity. Team leadership is pivotal for a leader to analyze the best appropriate approach based on the provided information to come up with an intelligent decision [69]. 


\section{Method}

\subsection{Design}

This study is descriptive-quantitative which aims to provide relevant information to the variables considered in this study using a survey design [70]. The term survey can be used to designate any research activity in which the investigator gathers data from a portion of a population for the purpose of examining the characteristics, opinions or intentions of that population [71].

\subsection{Research Participants}

This study involved 45 school leaders from 22 different Philippine Schools Overseas (PSOs) located in Bahrain, China, East Timor, Kingdom of Saudi Arabia, Kuwait, Libya, Oman, Qatar, United Arab Emirates, and Sabah. The participants were chosen due to the qualities that they hold and by virtue of knowledge and experience [9]. Majority of them are female ( $\mathrm{n}=31$ or $68.9 \%$ ), while the males are 14 or $31.1 \%$. In terms of age, they were dispersed into 5 age groups, $20-30$ years old ( $\mathrm{n}=4$ or $9 \%$ ); $31-40$ years old $(\mathrm{n}=11$ or $24 \%) ; 41-50$ years old $(\mathrm{n}=15$ or $33 \%)$; $51-60$ years old $(\mathrm{n}=13$ or $29 \%)$; and above $60(\mathrm{n}=2$ or $4 \%)$. Almost all of the respondents hold a top-level position (school principals) ( $\mathrm{n}=33$ or $73.3 \%$ ), whereas others are in the middle level (vice-principals and department/unit heads) $(\mathrm{n}=12$ or $26.7 \%)$. Their educational qualification varies but majority of them has a Masteral Degree ( $\mathrm{n}=23$ or $51.1 \%$ ). Other educational qualifications are college graduate $(\mathrm{n}=16$ or $35.6 \%$ ); Doctoral Degree ( $\mathrm{n}=4$ or $8.9 \%$ ), Post-Grad Degree ( $\mathrm{n}=1$ or $2.2 \%)$; and High School Graduate $(\mathrm{n}=1$ or $2.2 \%$ ). Overall, their years of managing the school ranges from 6-10 years, as the reported work experience of $46.7 \%$ $(\mathrm{n}=21)$; the work experience of the remaining $53.3 \%(\mathrm{n}=24)$ ranges from $1-5 ; 11-15 ; 16-20 ; 21-25$; and above 26 years, respectively.

\subsection{Research Instrument}

A self-made survey questionnaire was developed that was anchored on the Trait Theory of Leadership $[5,6]$; the Functional Leadership Theory [7,8]; and the Leadership Skills Theory [9] and supplemented by literature reviews from $[72,73,74,75,76,77,78]$. The survey questionnaire was used as the main data-gathering tool. The questionnaire was composed of four parts, part 1 sought the respondents' profile, part 2 determined the leader's core qualifications, part 3 determined the leader's emulating attributes, and part 4 determines the leader's core competencies. The questionnaire has a total of 135 -item statements followed by a 5-point scale asking the respondents how much they agree or disagree with the statements on the following scales: 1 -Strongly Disagree, 2 -Disagree, 3 -Neither Agree nor Disagree, 4 -Agree, 5
-Strongly Agree. Cronbach Alpha was used to assess the internal consistency and gauge the reliability of the statements in the survey instrument. The calculated Cronbach Alpha coefficients of the questionnaire indicated that the instrument used in this study to measure the core qualifications $(\alpha=.987)$, emulating attributes $(\alpha=.986)$, and core competencies $(\alpha=.989)$ have a relatively high internal consistency. It was also submitted to experts for content validation.

\subsection{Data Collection and Analysis}

Data collection was done in the following manner, first, the researcher formally sought permissions from the respondents involved in this study and the conference committee since data was collected by way of a paper survey and distributed to the PSO school leaders who were delegates of the $14^{\text {th }}$ Philippine School Overseas in Manila on 17-20 May 2016. The research was acknowledged as opportunistic and was approved by the conference committee. Upon permission of those concerned, the researcher personally administered and retrieved the questionnaires. Collected data were tallied, scored, tabulated and computed for analysis and interpretation using the SPSS software.

\section{Results and Discussion}

The results are divided into subsections, the factor analysis and regression analysis. Factor analysis was used for the identification of factors along core qualifications, emulating attributes, and core competencies of a leader. The Kaiser-Meyer-Olkin (KMO) measurement of adequacy and Bartlett test of sphericity were used to determine the applicability of factor analysis and to determine the factorability of the factors as a whole. The result value of Bartlett test of sphericity was significant (p $\left.=.000 ; \mathrm{x}^{2}=2590.672\right)$ and the Kaiser-Meyer-Olkin (KMO) measure is .669 . A KMO value of more that .50 was considered acceptable [79]. Thus, it is appropriate to proceed with factor analysis to examine the factors that constitute the leaders' core qualifications, emulating attributes, and core competencies. Secondly, regression analysis was carried out to identify the determinants of core competencies of leaders managing PSOs.

\subsection{Factor Analysis}

The rotated factor matrices for core qualifications, emulating attributes, and core competencies are shown in tables 1-3 below. Variables with more than 0.45 factor loadings were chosen because these are considered average [80].

Table 1 shows the rotated component matrix of core qualifications. Using the varimax rotation method with Kaiser normalization, factor 1 (leading people) comprised 
of 18 items (b1, b2, b3, b4, b5, b6, b7, b8, b9, b10, c1, c4, $\mathrm{c5}, \mathrm{c} 6, \mathrm{c} 7, \mathrm{c} 8, \mathrm{c} 9, \mathrm{~d} 7)$ with factor loadings ranging from .520 to .816 . Factor 2 (business coalition) comprised of 8 items $(\mathrm{d} 3, \mathrm{~d} 5, \mathrm{~d} 8, \mathrm{e} 1, \mathrm{e} 2, \mathrm{e} 3, \mathrm{e} 4, \mathrm{e} 5)$ with factor loadings ranging from .526 to .800 . The items in factor 3 (leading change) are a2, a4, a5, a6, a7, a9, a10 with factor loadings ranging from .503 to .764 . Factor 4 (results driven) comprised of 7 items (a3, a8, c2, c3, c9, d9, d10) with factor loadings ranging from .501 to .702 . Whilst, the items in factor 5 (business acumen) are c1, d1, d2, and d4 with factor loadings ranging from .523 to .782 .
The rotated component matrix of emulating attributes is shown in table 2. Factor 1 (conciseness) comprised 11 items (h1, h2, h3, h4, h5, i2, k1, 11, m1, m2, m5) with factor loadings ranging from .520 to .799 . Factor 2 (credibility) and factor 3 consisted of 8 items (f5, g5, j1, j2, j3, j4, j5, k5 and $\mathrm{g} 1, \mathrm{~g} 2, \mathrm{~g} 3, \mathrm{~g} 4, \mathrm{~g} 5, \mathrm{i} 1, \mathrm{i} 3, \mathrm{~m} 4)$ each with factor loadings ranging from .582 to .872 and .501 to .768 , respectively. Factor 4 (conviction) has 5 items $(\mathrm{k} 3,12,13,14,15)$ with factor loadings that range from .552 to .732 . Whereas, factor 5 (composure) comprised 4 items (f1, f2, f3, f4) and factor loadings that range from .551 to .744 .

Table 1. Rotated Component Matrix of Core Qualifications

\begin{tabular}{|c|c|c|c|c|}
\hline $\begin{array}{l}\text { Factor } 1 \\
\text { Leading people }\end{array}$ & $\begin{array}{l}\text { Factor } 2 \\
\text { Business coalition }\end{array}$ & $\begin{array}{l}\text { Factor } 3 \\
\text { Leading change }\end{array}$ & $\begin{array}{l}\text { Factor } 4 \\
\text { Results driven }\end{array}$ & $\begin{array}{l}\text { Factor } 5 \\
\text { Business acumen }\end{array}$ \\
\hline Factor loadings & Factor loadings & Factor loadings & Factor loadings & Factor loadings \\
\hline .705 (b1) & $.526(\mathrm{~d} 3)$ & .641 (a2) & .568 (a3) & $.523(\mathrm{c} 1)$ \\
\hline .697 (b2) & .608 (d5) & $.693(\mathrm{a} 4)$ & $.566(a 8)$ & $.714(\mathrm{~d} 1)$ \\
\hline .540 (b3) & $.659(\mathrm{~d} 8)$ & $.503(\mathrm{a} 5)$ & $.501(\mathrm{c} 2)$ & $.782(\mathrm{~d} 2)$ \\
\hline .693 (b4) & $.653(\mathrm{e} 1)$ & $.568(\mathrm{a} 6)$ & $.507(\mathrm{c} 3)$ & $.592(\mathrm{~d} 4)$ \\
\hline .778 (b5) & $.800(\mathrm{e} 2)$ & $.626(a 7)$ & .575 (c9) & \\
\hline .720 (b6) & $.778(\mathrm{e} 3)$ & .764 (a9) & .702 (d9) & \\
\hline .732 (b7) & $.743(\mathrm{e} 4)$ & .594 (a10) & $.689(\mathrm{~d} 10)$ & \\
\hline $.763(\mathrm{~b} 8)$ & $.527(\mathrm{e} 5)$ & & & \\
\hline .717 (b9) & & & & \\
\hline .816 (b10) & & & & \\
\hline $.680(\mathrm{c} 1)$ & & & & \\
\hline $.764(\mathrm{c} 4)$ & & & & \\
\hline .728 (c5) & & & & \\
\hline .805 (c6) & & & & \\
\hline $.650(\mathrm{c} 7)$ & & & & \\
\hline $.640(\mathrm{c} 8)$ & & & & \\
\hline $.520(\mathrm{c} 9)$ & & & & \\
\hline $.559(\mathrm{~d} 7)$ & & & & \\
\hline
\end{tabular}


Table 2. Rotated Component Matrix of Emulating Attributes

\begin{tabular}{|c|c|c|c|c|}
\hline $\begin{array}{l}\text { Factor } 1 \\
\text { Conciseness }\end{array}$ & $\begin{array}{l}\text { Factor } 2 \\
\text { Credibility }\end{array}$ & $\begin{array}{l}\text { Factor } 3 \\
\text { Connection }\end{array}$ & $\begin{array}{l}\text { Factor } 4 \\
\text { Conviction }\end{array}$ & $\begin{array}{l}\text { Factor } 5 \\
\text { Composure } \\
\end{array}$ \\
\hline Factor loadings & Factor loadings & Factor loadings & Factor loadings & Factor loadings \\
\hline .799 (h1) & .661 (f5) & $.628(\mathrm{~g} 1)$ & $.581(\mathrm{k} 3)$ & .738 (f1) \\
\hline $.714(\mathrm{~h} 2)$ & .582 (g5) & $.730(\mathrm{~g} 2)$ & $.691(12)$ & .744 (f2) \\
\hline $.594(\mathrm{~h} 3)$ & $.792(\mathrm{j} 1)$ & $.768(\mathrm{~g} 3)$ & $.542(13)$ & .661 (f3) \\
\hline $.705(\mathrm{~h} 4)$ & $.829(\mathrm{j} 2)$ & $.749(\mathrm{~g} 4)$ & $.732(14)$ & $.551(\mathrm{f} 4)$ \\
\hline $.622(\mathrm{~h} 5)$ & $.872(\mathrm{j} 3)$ & .613 (g5) & $.552(15)$ & \\
\hline .536 (i2) & $.757(\mathrm{j} 4)$ & .560 (i1) & & \\
\hline $.687(\mathrm{k} 1)$ & $.722(j 5)$ & $.520(\mathrm{i} 3)$ & & \\
\hline $.539(11)$ & $.632(\mathrm{k} 5)$ & $.501(\mathrm{~m} 4)$ & & \\
\hline $.520(\mathrm{~m} 1)$ & & & & \\
\hline $.663(\mathrm{~m} 2)$ & & & & \\
\hline .667 (m5) & & & & \\
\hline
\end{tabular}

Table 3. Rotated Component Matrix of Core Competencies

\begin{tabular}{|l|l|l|l|}
\hline Factor 1 & Factor 2 & Factor 3 \\
Market Knowledge & Strategic Orientation & Factor loadings & $\begin{array}{l}\text { Factor 4 } \\
\text { Teamwork }\end{array}$ \\
\hline Factor loadings & Factor loadings & $.608(\mathrm{n} 3)$ & Factor loadings \\
\hline $.708(\mathrm{p} 1)$ & $.542(\mathrm{n} 2)$ & $.574(\mathrm{o} 3)$ & $.502(\mathrm{q} 3)$ \\
$.766(\mathrm{p} 2)$ & $.585(\mathrm{n} 5)$ & $.546(\mathrm{r} 2)$ & $.755(\mathrm{t} 2)$ \\
$.790(\mathrm{p} 3)$ & $.619(\mathrm{o} 1)$ & $.694(\mathrm{r} 4)$ & $.708(\mathrm{t} 3)$ \\
$.746(\mathrm{p} 4)$ & $.558(\mathrm{o} 4)$ & $.713(\mathrm{~s} 1)$ & $.607(\mathrm{u} 2)$ \\
$.775(\mathrm{p} 5)$ & $.680(\mathrm{o})$ & $.721(\mathrm{~s} 2)$ & \\
$.750(\mathrm{q} 1)$ & $.594(\mathrm{t})$ & $.696(\mathrm{~s} 3)$ & $.590(\mathrm{~s} 4)$ \\
$.726(\mathrm{q} 2)$ & $.553(\mathrm{u} 1)$ & $.630(\mathrm{~s} 5)$ & \\
$.696(\mathrm{q} 3)$ & $.696(\mathrm{u} 3)$ & $.596(\mathrm{t} 1)$ & \\
$.738(\mathrm{q} 4)$ & $.652(\mathrm{u} 4)$ & & \\
$.684(\mathrm{q} 5)$ & $.637(\mathrm{u} 5)$ & & \\
& $.589(\mathrm{v} 1)$ & & \\
& $.758(\mathrm{v} 3)$ & $.660(\mathrm{v} 4)$ & \\
\hline
\end{tabular}

Table 3 presented the rotated component matrix of core competencies. As shown, factor 1 (market knowledge) consisted of 10 items (p1, p2, p3, p4, p5, q1, q2, q3, q4, q5) with factor loadings ranging from .684 to .790 . Factor 2 (strategic orientation) comprised 14 items (n2, n5, o1, o4, $\mathrm{o} 5, \mathrm{t5}, \mathrm{u} 1, \mathrm{u} 3, \mathrm{u} 4, \mathrm{u} 5, \mathrm{v} 1, \mathrm{v} 3, \mathrm{v} 4, \mathrm{v} 5)$ with factor loadings that range from .542 to .758 . Factor 3 (change management) has 10 items (n3, o3, r2, r4, s1, s2, s3, s4, s5, t1) with factor loadings ranging from .546 to .721 . Factor 4 comprised 4 items $(\mathrm{q} 3, \mathrm{t} 2, \mathrm{t} 3, \mathrm{u} 2)$ with factor loadings ranging from .502 to .755 .

Factor summaries are show in the succeeding tables.

Table 4 shows the PSO school leader's main core qualifications; they are leading people, business coalition, leading change, results driven and business acumen.

Table 4. Factors of Core Qualifications

\begin{tabular}{|l|l|}
\hline Factors & Descriptions \\
\hline Factor 1 & Leading people \\
\hline Factor 2 & Business coalition \\
\hline Factor 3 & Leading change \\
\hline Factor 4 & Results driven \\
\hline Factor 5 & Business acumen \\
\hline
\end{tabular}

Table 5 shows the PSO school leader's main emulating 
attributes; they are conciseness, credibility, connection, conviction, and composure.

Table 5. Factors of Emulating Attributes

\begin{tabular}{|l|l|}
\hline Factors & Descriptions \\
\hline Factor 1 & Conciseness \\
\hline Factor 2 & Credibility \\
\hline Factor 3 & Connection \\
\hline Factor 4 & Conviction \\
\hline Factor 5 & Composure \\
\hline
\end{tabular}

Table 6 shows the PSO school leader's main core competencies; they are market knowledge, strategic orientation, change management, and teamwork.

Table 6. Factors of Core Competencies

\begin{tabular}{|l|l|}
\hline Factors & Descriptions \\
\hline Factor 1 & Market Knowledge \\
\hline Factor 2 & Strategic Orientation \\
\hline Factor 3 & Change Management \\
\hline Factor 4 & Teamwork \\
\hline
\end{tabular}

\subsection{Regression Analyses}

\subsubsection{Core Qualifications and Core Competencies}

The regression of core qualifications and core competencies reported that two components of core qualifications are significant, they are: leading people $(\mathrm{B}=1.531 ; \mathrm{t}=4.674$; sig. $=.000)$; and business coalition $(\mathrm{B}=1.865 ; \mathrm{t}=2.736$; sig. $=.009)$. But among the two significant variables, leading people has a stronger coefficient (Beta $=.575)$ than business coalition $(\mathrm{Beta}=.337)$. The $\mathrm{R}$ is .863 with an adjusted $\mathrm{R}$-square of .732 , this signifies that $73.2 \%$ of the variation on core competencies can be attributed to leading people and business coalition. The $\mathrm{F}$ statistics is 61.117 and is significant at .000 . The collinearity analysis revealed a tolerance of .402 and VIF of 2.489 which means that there is no problem of multicollinearity since the VIF value did not exceed 4.0 or the tolerance is not less than 0.2 [81] The overall analysis thereby implies that leading people and business coalition significantly determine the PSO's school leaders' core competencies.

\subsubsection{Emulating Attributes and Core Competencies}

The regression of emulating attributes and core competencies, revealed that two components of emulating attributes are significant, conciseness $(B=2.568 ; \mathrm{t}=4.534$; sig. $=.000)$ and composure $(B=4.379 ; \mathrm{t}=2.878$, sig. $=.006)$ with positive beta regression coefficients. Whilst, among the two significant variables, conciseness has a stronger coefficient $(\mathrm{Beta}=.560)$ than composure $(\mathrm{Beta}=.355)$. The $\mathrm{R}$ is .866 with an adjusted $\mathrm{R}$-square of .738 , this points out that $73.8 \%$ of the variation on core competencies in terms of emulating attributes can be attributed to conciseness and composure. The F statistics is 62.824 and is significant at .000 . The collinearity analysis revealed a tolerance of .392 and VIF of 2.554, therefore there is no problem of multicollinearity since the VIF value did not exceed 4.0 or the tolerance is not less than 0.2 [81] Based on the findings presented, it is highly acknowledged that conciseness and composure significantly determine the PSO's school leaders' core competencies.

\section{Conclusions}

Managing a school is generally viewed as an essential factor in the success of the PSOs. This is because of the undeniable significance of the role of school leaders in managing and running the school. It is said that the school management is the heart which the entire educational system can thrive and survive. Based on the findings, leading people, business coalition, conciseness, and composure were identified as the determinants of core competencies of school leaders managing the Philippine Schools Overseas. School leaders possessing the right core competencies tend to be more effective and efficient in the way they manage the institution. It also means to say that successful management can still be achieved even in the presence of some unlikely conditions, extreme pressures, and other external factors as long as the leader is open to change, has a strong sense of business coalition, and leads people with composure and conciseness. It is highly recommended that school leaders should pursue professional development activities to equip them with the needed competencies in managing the school. For PSOs, there should be a guiding policy on determining the required core competencies of school leaders to meet the qualifying standards in appointing or employing school officials as an assurance of competence, quality, and leadership skills or ability. Nevertheless, the level of the school leaders' core qualification, emulating attributes, and core competencies are not absolute; it can still change over time and fluctuate under different circumstances, of which are no longer covered by this research, thereby, opening new opportunities for further studies exploring different variables.

\section{REFERENCES}

[1] Commission on Filipinos Overseas (2016). 2014 CFO Compendium of Statistics on International Migration, 4th Edition. Online Available from http://www.cfo.gov.ph/ima ges/pdf/pdf-migration/2014-CFO-Statistical-Compendium. pdf

[2] Commission of Filipinos Overseas (2017). 2015 CFO Statistics on Philippine Migration. Available online from: http://www.cfo.gov.ph/images/pdf/2017/2015compendium stats-insidepages-2017-06-29.pdf 
[3] Qatar Day (2017 May). List of registered Filipino school outside the Philippines. QatarDay.com. Available online from: http://www.qatarday.com/blog/information/list-of-r egistered-filipino-school-outside-the-philippines/26310?pg $=1$

[4] Mehri, A., \& Ramezan, J. (2016). The competency of managers in 21 st century. Bulletin de la Société Royale des Sciences de Liège, 85, 967-973

[5] Stogdill, R.M. (1974). Handbook of leadership: A survey of the literature, New York: Free Press

[6] McCall, M.W. Jr. and Lombardo, M.M. (1983). Off the track: Why and how successful executives get derailed. Greenboro, NC: Centre for Creative Leadership

[7] Hackman, J. R., \& Walton, R. E. (1986). Leading groups in organizations. In P. S. Goodman, \& Associates (Eds.), Designing effective work groups (pp. 72-119). San Francisco, CA: Jossey-Bass

[8] McGrath, J. E. (1962). Leadership behavior: Requirements for leadership training. Prepared for U.S. Civil Service Commission Office of Career

[9] Mumford, M. D., Zaccaro, S. J., Johnson, J. F., Diana, M., Gilbert, J. A., \& Threlfall, K. V. (2000). Patterns of leader characteristics: Implications for performance and development. The Leadership Quarterly, 11(1), 115-133

[10] Harrison, B. \& Cohens, I. (2016). Trait Theory of Leadership. In Organization and Administration in Recreation, Sport and Leisure Management. Retrieved from: https://oer.missouriwestern.edu/rsm424/chapter/trait-theor y-of-leadership/

[11] Kumar, S., Adhish, V. S., \& Deoki, N. (2014). Making sense of theories of leadership for capacity building. Indian journal of community medicine: official publication of Indian Association of Preventive \& Social Medicine, 39(2), $82-6$

[12] Guramatunhu Cooper, Nyasha M. (2017), Theory Leadership from Africa: Examples of Trait Theory, in Jean Lau Chin, Joseph E. Trimble, Joseph E. Garcia (ed.) Global and Culturally Diverse Leaders and Leadership (Building Leadership Bridges, Volume) Emerald Publishing Limited, pp.3 - 19

[13] Allport, G.W. (1961). Pattern and growth in personality. New York: Holt, Rinehart \& Winston

[14] Gray, T. D., \& Callahan, J. (2008). Skills of the Spartans: Exploring leadership in 300. Journal of Leadership Education, 7(2), 79-98

[15] Schutz, W. C. 1961. The ego, FIRO theory and the leader as completer. In L. Petrullo \& B. M. Bass (Eds.), Leadership and interpersonal behavior: 48-65. New York: Holt, Rinehart \& Winston

[16] Morgeson, F. P., DeRue, D. S., \& Karam, E. P. (2010). Leadership in teams: A functional approach to understanding leadership structures and processes. Journal of management, 36(1), 5-39

[17] Baez, Mhykeah (2016). Skills Theory of Leadership. In Organization and Administration in Recreation, Sport and Leisure Management. Retrieved from: https://oer.missouri western.edu/rsm424/chapter/skills-theory-of-leadership/
[18] Amanchukwu, R. N., Stanly, G. J. \& Ololube, N. P. (2015) A review of Leadership theories, principles and styles and their relevance to Educational Management. Management, 5 (1), 6- 14

[19] Uzohue, C., Yaya, J., \& Akintayo, O. A. (2016). A review of leadership theories, principles, styles and their relevance to management of health science libraries in Nigeria. Journal of Educational Leadership and Policy, 1(1), 17-26

[20] Pillai, R. (2000). Leadership: Theory and Practice. Peter G. Northouse, Sage Publications, Thousand Oaks, CA, 1997. Journal of Organizational Behavior, 21(1), 115-117

[21] Northouse, P. G. (2018). Leadership: Theory and practice. Sage publications

[22] Abbas, G., \& Riaz, M. N. (2012). Relationship between transformational leadership style and innovative work behavior in educational institutions. Journal of Behavioral Sciences, 22(3), 18

[23] Kolzow, D. R. (2014). Leading from within: Building organizational leadership capacity. International Economic Development Council, 1-314

[24] Adams, C. A. (2014). Sustainability and the company of the future. Reinventing the Company in the Digital Age, 411-430

[25] Day, C. (2011). Successful school leadership: Linking with learning and achievement. McGraw-Hill Education (UK)

[26] Detsky, A. S. (2011). How to be a good academic leader. Journal of general internal medicine, 26(1), 88-90

[27] Jansen, J. J., George, G., Van den Bosch, F. A., \& Volberda, H. W. (2008). Senior team attributes and organizational ambidexterity: The moderating role of transformational leadership. Journal of Management Studies, 45(5), 982-1007

[28] Best, A., \& Holmes, B. (2010). Systems thinking, knowledge and action: towards better models and methods. Evidence \& Policy: A Journal of Research, Debate and Practice, 6(2), 145-159

[29] Ligthelm, A. A. (2010). Entrepreneurship and small business sustainability. Southern African Business Review, 14(3)

[30] Baharom, M. N. R., Salleh, R., Sivapalan, S., Ali, R. M. M., \& Abdullah, A. (2014). Gauging Business Acumen Level of Technical Students from Universiti Teknologi PETRONAS: Views from the Malaysian Industry. Procedia - Social and Behavioral Sciences, 116, 4683-4688. https://doi.org/10.1 016/j.sbspro.2014.01.1008

[31] Stallard, M. L. (2015). Connection Culture: The Competitive Advantage of Shared Identity, Empathy, and Understanding at Work. American Society for Training and Development

[32] Ali, A. S. A., Elmi, H. O., \& Mohamed, A. I. (2013). The Effect of Leadership Behaviors on Staff Performance In Somalia. Educational Research International, 2(2).

[33] Llopis, Glenn. (2014 June 30). Change Management Requires Leadership Clarity and Alignment. Forbes. Available in: https://www.forbes.com/sites/glennllopis/201 4/06/30/change-management-requires-leadership-clarity-an d-alignment/\#54ea05b73e3 
[34] Trager, R., Ross, S. D., \& Reynolds, A. (2017). The law of journalism and mass communication. Cq Press

[35] Darrat, M. A., Mulki, J. P., \& Swimberghe, K. (2017). The Interplay of Emotion Regulation and Sales Experience in Salesperson Conflicts: Evidence from an Emerging Economy. Journal of Global Marketing, 30(2), 99-109

[36] Kouzes, J. M., \& Posner, B. Z. (2011). Credibility: How leaders gain and lose it, why people demand it (Vol. 244). John Wiley \& Sons

[37] Amabile, T. M., Schatzel, E. A., Moneta, G. B., \& Kramer, S. J. (2004). Leader behaviors and the work environment for creativity: Perceived leader support. The Leadership Quarterly, 15(1), 5-32

[38] Brookhart, S. M. (2017). How to give effective feedback to your students. ASCD

[39] Mortensen, K. W. (2012). The Laws of Charisma. Laws of Charisma - Business Book Summaries, 1. Retrieved from http://content.ebscohost.com/ContentServer.asp? $\mathrm{T}=\mathrm{P} \& \mathrm{P}=$ AN\&K $=70708321 \& S=R \& D=$ qbh \&EbscoContent $=$ dGJyM NHr7ESeqLQ4v+vlOLCmr0qeprBSrq+4SLGWxWXS\&C ontentCustomer=dGJyMOzpr1Cvpq5KuePfgeyx44Dt6fIA

[40] Cabane, O. F. (2011). The Charisma Myth. Master the Art of Personal Magnetism, 346

[41] Richardson, L., Houston, D., \& Hadjiharalambous, C. S. (2001). Public confidence in the leaders of American governmental institutions. What is it about Government that Americans Dislike, 83-97

[42] Levine, M. (2016). Experiences of trust in longer-lasting formal youth mentoring relationships (Doctoral dissertation, University of Massachusetts Boston)

[43] Kouzes, J. M., \& Posner, B. Z. (2010). The truth about leadership. Soundview Executive Book Summaries

[44] Warrick, D. D. (2011). The urgent need for skilled transformational leaders: Integrating transformational leadership and organization development. Journal of leadership, Accountability, and Ethics, 8(5), 11-26

[45] Robinson, F. P., Gorman, G., Slimmer, L. W., \& Yudkowsky, R. (2010, July). Perceptions of effective and ineffective nurse-physician communication in hospitals. In Nursing forum (Vol. 45, No. 3, pp. 206-216). Blackwell Publishing Inc

[46] Engleberg, I. N., Ward, S. M., Disbrow, L. M., Katt, J. A., Myers, S. A., \& O'Keefe, P. (2017). The development of a set of core communication competencies for introductory communication courses. Communication Education, 66(1), $1-18$

[47] Acosta, Alexander. (2017). A panorama of conflict mediation experiences of a selected group of administrators representing the Philippine School Overseas. International Journal of Educational Policy Research and Review Vol.4 (7), pp. 158 - 168 July, 2017. Review Vol.4. pp. 158 - 168

[48] Sharma, N., Sharma, N., Sahay, B. S., Sahay, B. S., Sarma, P. R. S., \& Sarma, P. Shirey, M. R. (2011). Establishing a sense of urgency for leading transformational change. Journal of Nursing Administration, 41(4), 145-148

[49] Stanley, D. (2016). Congruent Leadership. Clinical
Leadership in Nursing and Healthcare: Values into Action, 59-89

[50] Kaminska, A. (2016). One principal's communication style: A journey toward building a strong school community. Hofstra University

[51] Fullan, M. (2009). Motion leadership. ExecuGo media

[52] Asrar-ul-Haq, M., \& Kuchinke, K. P. (2016). Impact of leadership styles on employees' attitude towards their leader and performance: Empirical evidence from Pakistani banks. Future Business Journal, 2(1), 54-64

[53] Griffith, A. N., \& Larson, R. W. (2016). Why trust matters: How confidence in leaders transforms what adolescents gain from youth programs. Journal of Research on Adolescence, 26(4), 790-804

[54] Mithas, S., Krishnan, M. S., \& Fornell, C. (2005). Why do customer relationship management applications affect customer satisfaction? Journal of Marketing, 69(4), 201-209

[55] Herrera, M. E. B. (2015). Creating competitive advantage by institutionalizing corporate social innovation. Journal of Business Research, 68(7), 1468-1474

[56] Lewke, R. \& Kelner, S. (2007 November 1). What Does It Mean to Have Market Knowledge? Available in: Https:/www.cio.com/article/2437737/strategy/what-does-i t-mean-to-have-market-knowldge-.html

[57] Kim, Y., \& Park, H. (2017). Is there Still a PR Problem Online? Exploring the Effects of Different Sources and Crisis Response Strategies in Online Crisis Communication via Social Media. Corporate Reputation Review, 20(1), 76-104

[58] Hussein, O (2017 August 9). The importance of commercial skills in management development. Available in: https://mdatraining.com/blog2017/08/09/importance-com mercial-skills-management-development/

[59] Huber, S. G., \& Pashiardis, P. (2008). The recruitment and selection of school leaders. International Handbook on the Preparation and Development of school leaders, 176-202

[60] Abbas, W., \& Asghar, I. (2010). The Role of Leadership in Organizational Change: Relating the successful Organizational Change with Visionary and Innovative Leadership

[61] Cloud, R. C. (2010). Epilogue: Change leadership and leadership development. New Directions for Community Colleges, 2010(149), 73-79

[62] Folaron, J. (2005). The human side of change leadership. Quality Progress, 38(4), 39

[63] Reeves, D. B. (2009). Leading change in your school: How to conquer myths, builds commitment, and gets results. Ascd. Available in: http://www.ascd.org/publications/book s/109019.aspx

[64] Babiak, K., \& Thibault, L. (2008). Managing inter-organisational relationships: The art of plate spinning. International journal of sport management and marketing, $3(3), 281-302$

[65] Slipicevic, O., \& Masic, I. (2012). Management knowledge 
and skills required in the health care system of the Federation Bosnia and Herzegovina. Materia socio-medica, 24(2), 106

[66] Bassi, L., \& McMurrer, D. (2007). Maximizing your return on people. harvard business review, 85(3), 115

[67] Kumar, D., \& Abdullah, O. Y. (2013). Capability Development: Enhancing Employee Potential through Strategic Competency Building and People Development. International Journal of Management and Social Sciences ResearchXplore International Research Journal Consortium, 2(2), 2319-4421

[68] Hambrick, D. C. (2003). On the staying power of defenders, analyzers, and prospectors. The Academy of Management Executive, 17(4), 115-118

[69] Lee, P., Gillespie, N., Mann, L., \& Wearing, A. (2010). Leadership and trust: Their effect on knowledge sharing and team performance. Management learning, 41(4), 473-491

[70] Sousa, V. D., Driessnack, M., \& Mendes, I. A. C. (2007). An overview of research designs relevant to nursing: Part 1: quantitative research designs. Revista latino-americana de enfermagem, 15(3), 502-507

[71] Maboe, K. A., \& De Villiers, L. (2011). Computer-assisted instruction in nursing education in South Africa. Africa Journal of Nursing and Midwifery, 13(1), 93-104

[72] Ruderman, Marian N., Cathleen Clerkin, and Carol Connolly (2014). "Leadership development beyond competencies moving to a holistic approach." Greensboro, NC: Center for Creative Leadership

[73] Fullan, M. (2002). Principals as leaders in a culture of change. Educational leadership, 59(8), 16-21

[74] Krasnoff, B. (2015). Leadership qualities of effective principals. Education Northwest, 1-10

[75] Wallace Foundation. (2013). The school principal as leader: Guiding schools to better teaching and learning. Available online from http://www. wallacefoundation.org/knowledge -center/ school-leadership/effective-principalleadership/Pa ges/The-School-Principal-asLeader-Guiding-Schools-to-B etter-Teachingand-Learning.aspx

[76] Goolamally, N., \& Ahmad, J. (2014). Attributes of School Leaders Towards Achieving Sustainable Leadership: A Factor Analysis. Journal of Education and Learning, 3(1), $122-133$

[77] George, B., \& McLean, A. (2011). Why leaders lose their way. Strategy \& leadership, 35(3), 4-11

[78] Williams, Terri (2017). Why Integrity Remains One of the Top Leadership Attributes. Available online from: https://execed.economist.com/blog/industry-trends/why-int egrity-remains-one-top-leadership-attributes

[79] Venkaiah, K., Brahmam, G. N., \& Vijayaraghavan, K. (2011). Application of factor analysis to identify dietary patterns and use of factor scores to study their relationship with nutritional status of adult rural populations. Journal of health, population, and nutrition, 29(4), 327-38

[80] Tabachnick, B. G., Fidell, L. S., \& Ullman, J. B. (2007). Using multivariate statistics (Vol. 5). Boston, MA: Pearson

[81] Hair Jr., J.F., Black, W.C., Babin, B.J. and Anderson, R.E. (2010) Multivariate Data Analysis: A Global Perspective. 7th Edition, Pearson Education, Upper Saddle River 